\title{
Mutations and differential expression of the ras family genes in human nasal polyposis
}

\author{
APOSTOLOS ZARAVINOS $^{1}$, JOHN BIZAKIS ${ }^{2}$, GIANNOULA SOUFLA ${ }^{1}$, \\ GEORGE SOURVINOS ${ }^{1}$ and DEMETRIOS A. SPANDIDOS ${ }^{1}$ \\ ${ }^{1}$ Laboratory of Virology, Medical School, University of Crete, Heraklion; ${ }^{2}$ Department of \\ Otolaryngology, University Hospital of Heraklion, Crete, Greece
}

Received August 20, 2007; Accepted September 18, 2007

\begin{abstract}
Although it is well established that ras genes contribute to tumourigenesis either through the accumulation of mutations or by aberrant expression in a wide range of human cancers, little is known regarding their involvement in human nasal polyps (NPs). In the present study, the occurrence of mutations in codons 11 and 12 of the ras family genes was examined by PCR/RFLP and direct sequencing in 23 human NPs and their adjacent turbinates, as well as in turbinates from 13 control subjects. Moreover, the expression pattern of ras mRNA levels was assessed in NP specimens and compared to adjacent and control tissues. K-ras codon 11 and 12 mutations were detected in 17 and $35 \%$ of NPs, respectively, and were found in the adjacent inferior turbinate (AIT) (22 and 16\%, respectively) and adjacent middle turbinates (AMT) (16 and $26 \%$, respectively). $\mathrm{K}$ - and $\mathrm{H}$-ras expression levels were elevated, whereas N-ras mRNA levels were lower in NPs and adjacent turbinates as compared to the control tissues. K-ras mRNA levels were up-regulated in advanced-stage polyps $(\mathrm{P}=0.037)$, while $\mathrm{N}$-ras levels were found elevated in small polyps $(\mathrm{P}=0.046)$. Statistically significant negative correlations between $\mathrm{K}$ - and $\mathrm{N}$-ras expression profiles arose in NPs and AITs ( $\mathrm{P}=0.009$ and 0.003 , respectively). This, to our knowledge, is the first report on ras mutations and expression analysis in NPs. Our findings suggest a potential key role for activated members of ras family genes in terms of their contribution to the development of NPs as well as to the hypertrophy of adjacent turbinates.
\end{abstract}

\section{Introduction}

Nasal polyps (NPs) are grapelike structures of unknown etiology which arise from the nasal and sinus mucosa. They

Correspondence to: Professor D.A. Spandidos, University of Crete, Laboratory of virology, Medical School, Heraklion 71100, Crete, Greece

E-mail: spandidos@spandidos.gr

Key words: ras genes, nasal polyps, mutations, gene expression, real-time RT-PCR have a predilection for the middle turbinate, middle meatus and the ethmoids, while discrete polyps are rarely seen on the inferior turbinate or septum (1). Nasal polyposis occurs as frequently in patients with atopy as in the general population. Polyp tissue is characterised by the presence of chronic inflammation in which eosinophils are the most prevalent infiltrating inflammatory cell type (2). Additional features of NPs include varying degrees of thickening basement membrane and fibrosis in the stroma $(3,4)$, similar to that recently described in asthma (5). The mechanism underlying these structural abnormalities is as yet unknown.

Members of the ras family genes (K-ras, H-ras and N-ras) encode for a $21 \mathrm{kDa}$ protein (p21) located on the inner surface of the plasma membrane with a farnesyl molecule attached to its carboxy-terminus. Ras genes are involved in a wide range of human tumours. The most common mechanism for their activation involves point mutations which abolish the GTPase activity of p21 and thus remain constitutively activated (6). Representative tumours which harbour mutant K-ras alleles are those of the pancreas, lung and colon. K-ras mutations have also been detected in various other tumours including the cervix of the uterus (7), breast (8), kidney (9), stomach (10) and testis (11). Ras mutations are most often localised in codons 12, 13 and 61. Rare variants of point mutations at codons 11,18 and 59 have been reported in a few human tumours (12-14).

In vitro experiments have shown that, apart from the mutant form, the overproduction of normal Ras protein is sufficient to confer a transforming potential to cultured cells (15). Furthermore, experiments on human tumour specimens have revealed that elevated levels of ras-encoded RNA and protein are a frequent feature in a wide range of human cancers (16). In addition, elevated levels of ras mRNA have been associated with particular clinicopathological parameters, such as a favourable prognosis in head and neck cancer (17), which suggests a protective role for ras gene overexpression in human tumours. Indeed, it has been proposed that ras genes play a dual role, acting as both oncogenes and oncosuppressors (18). Interestingly, in several cases overexpression was not accompanied by point mutations suggesting an alternative function of ras genes, apart from structural alterations, in carcinogenesis (19).

In the present study, a sensitive PCR-RFLP assay, in combination with direct sequencing of the PCR product, was 
employed. The aim was to detect codon 11 and 12 point mutations in $\mathrm{K}-$, $\mathrm{H}-$ and $\mathrm{N}$-ras genes, their adjacent inferior turbinates (AITs) and adjacent middle turbinates (AMTs), taken from 23 human NP specimens. Control inferior turbinates (CITs) and control middle turbinates (CMTs) from 13 disease-free subjects were also examined. Moreover, the expression levels of tumour ras mRNA were compared to those of the corresponding AITs and AMTs, as well as to the control turbinates, using real-time RT-PCR. We detected K-ras codon 11 and 12 mutations in NPs at 17 and $35 \%$, respectively. K-ras codon 11 and 12 mutations were also found in AITs (22 and 16\%, respectively) and AMTs (16 and $26 \%$, respectively), whereas all control tissues were found to be wild-type for each one of the ras genes. K- and $\mathrm{H}$-ras expression levels were higher in the NPs and adjacent turbinates than in the control turbinates, while N-ras mRNA levels in the NPs and adjacent turbinates were underexpressed regarding the control tissues.

\section{Patients and methods}

Subjects. Biopsies of the NPs and mucosa from the AIT and AMT were obtained from a total of 23 patients with CRS/NP (17 men and 6 women; average age, 51; range, 21-73 years). All polyps arose from the middle turbinate, middle meatus or ethmoidal sinuses, and were multiple and bilateral. From patients 1-4, no middle turbinate was obtained. Following histopathological examination of the specimens, the NPs were classified into grades I, II and III according to their size (20) (Table I). All patients suffered from sneezing, rhinorrhea, headaches, nasal obstruction and hyposmia or anosmia, and had undergone a nasal polypectomy at least once in the past. NP patients had not taken any drug (topical or systemic corticosteroids) for at least one month prior to surgery.

Our control group was composed of 13 subjects, with no history of nasal or allergic symptoms of any kind, undergoing nasal corrective surgery for nasal septum deformity. During these operations, a biopsy from the mucosa of the CIT and CMT of each patient was acquired. No patients in the group had been administered corticosteroids for at least one month preceding surgery.

All study groups were submitted to a serum determination of total-IgE, specific-IgE (RAST) and to hypersensitivity skin tests for a number of allergens. Patients with allergies or asthma were excluded from the study. Clinical parameters, such as age, sex, smoking and alcohol habits, were available for all patients and control subjects.

The Ethics Committee of the University of Crete approved the study and all participants (patients and control subjects) were aware of the scope of the study and gave their informed written consent.

DNA extraction, oligonucleotide primers and PCR amplification. Genomic DNA was extracted using proteinase $\mathrm{K}$ followed by phenol extraction and ethanol precipitation according to standard procedures. All specimens were examined for the presence of amplifiable DNA using a set of primers for the $B$-globin gene. Primer pairs and amplification conditions for the PCR-RFLP were used as previously described (19).
Table I. Clinicopathological characteristics of patients and control subjects.

Nasal polyps and

Control

adjacent turbinates

mucosae

\begin{tabular}{lrr}
\hline Subjects (no.) & $23^{\mathrm{a}}$ & 13 \\
Sex (M/F) & $17 / 6$ & $10 / 3$ \\
Age (years) & & \\
$\quad$ Mean & 49.3 & 33.4 \\
$\quad$ Range & $21-73$ & $12-68$ \\
Smoke (yes/no) & $8 / 15$ & $5 / 8$ \\
Alcohol (yes/no) & $7 / 16$ & $4 / 9$ \\
Aspirin (tolerance/ & $6 / 17$ & $13 / 0$ \\
intolerance) & & \\
NP stage (grade) & & \\
$\quad$ I & 3 & \\
$\quad$ II & 9 & \\
$\quad$ III & 11 & \\
\hline
\end{tabular}

a 19 adjacent middle turbinates.

RFLP analysis and direct sequencing. K- and N-ras: 10-40 $\mu 1$ aliquots of the amplification products were digested for $16 \mathrm{~h}$ with $30 \mathrm{U}$ BstNI. H-ras: 10-40 $\mu 1$ aliquots of the amplification products were digested for $16 \mathrm{~h}$ with $30 \mathrm{U}$ Msp $\mathrm{I}$. RFLP products were analysed on $3 \%$ agarose gel and photographed on a UV light transilluminator. DNA, from the cell lines SW480 bearing a homozygous mutation in K-ras codon 12 , and EJ, which is mutant at the same codon of the H-ras gene, were used as positive controls, respectively. PCR products were purified with the Qiaquick PCR purification kit (Qiagen Inc.) and a sequencing reaction was performed on a GeneAmp 9600 thermal cycler using the ABI PRISM BigDye Terminator Cycle Sequencing Ready Reaction Kit (PE Applied Biosystems, Tokyo, Japan). Sequences were analysed using ABI PRISM 310 Genetic Analyser (PE Applied Biosystems) to determine sequence configuration at codons 11,12 and 13 . The sequences were double-checked by using the forward and reverse primers separately (Fig. 1).

RNA extraction and reverse transcription. Tissue specimens were homogenised in TRIzol ${ }^{\circledR}$ reagent (Invitrogen, Carlsbad, CA) using a power homogeniser followed by chloroform addition and centrifugation. Total-RNA was precipitated from the supernatant with isopropanol, washed with $75 \%$ ethanol and resuspended in $50 \mu 1$ DEPC-treated water. RNA concentration and purity was calculated after its $260 \mathrm{~nm}$ absorbance and 260/280 nm absorbance ratio, respectively, were measured on a UV spectrophotometer. cDNA was synthesised by reverse transcription (RT) with the StrataScript ${ }^{\circledR}$ First-Strand Synthesis System. In detail, first strand buffer 

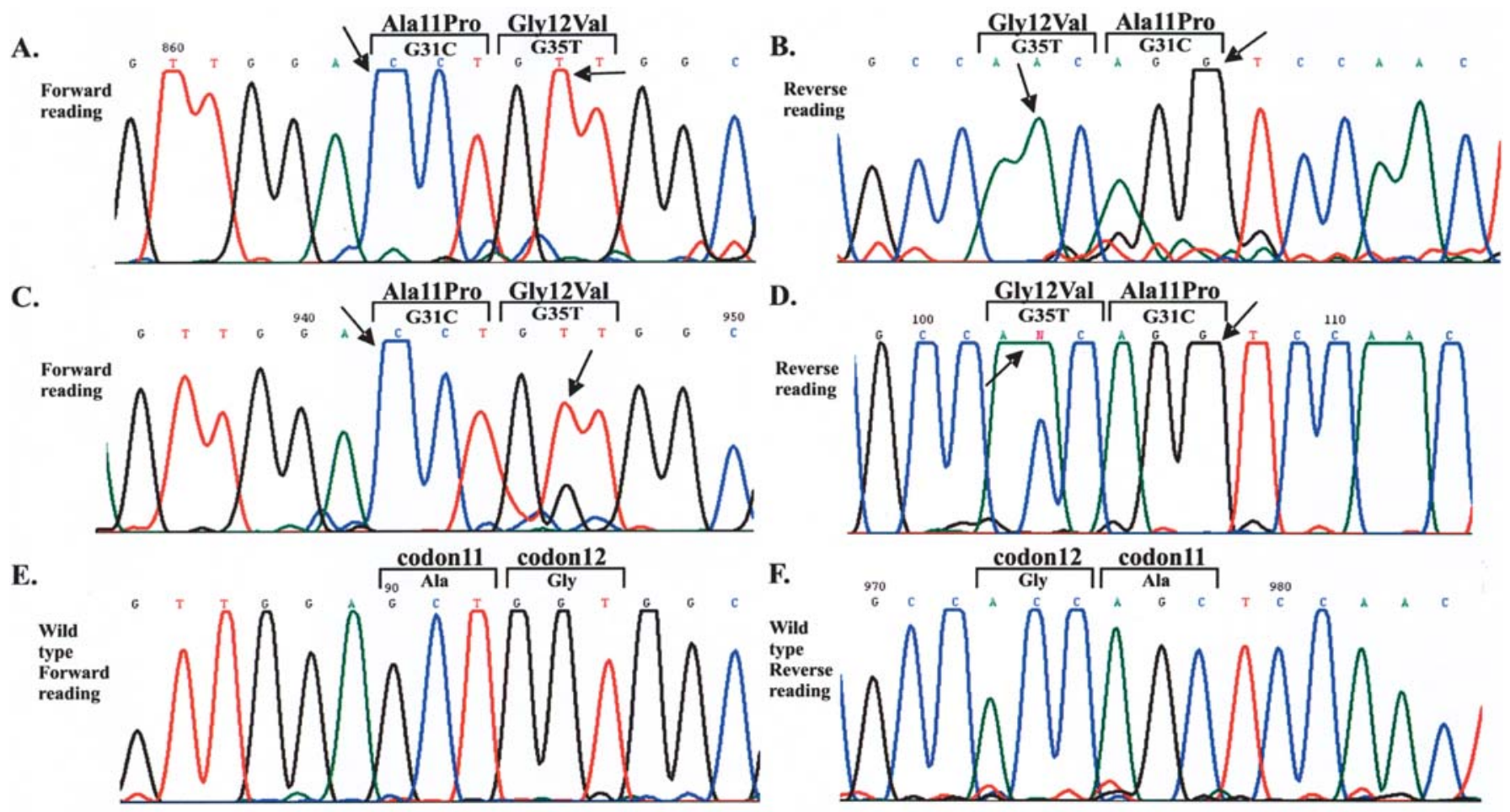

E.

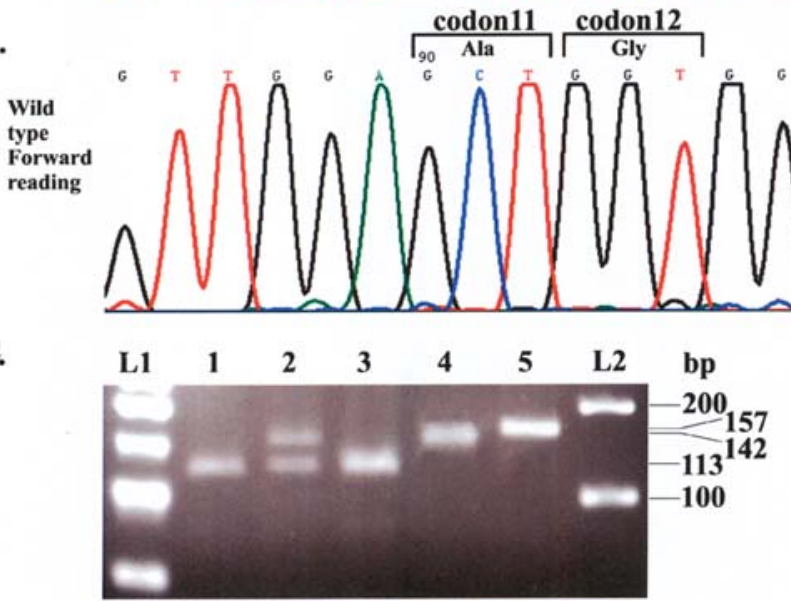

F.

Figure 1. Sequencing electrophoretograms of the same patients depicting forward (A, C and E) and reverse (B, D and F) readings. (A and B) Arrows indicate homozygous K-ras codon 11 (GCT $\rightarrow$ CCT; Ala11Pro) and 12 (GGT $\rightarrow$ GTT; Gly12Val) mutations. (C and D) Arrows show homozygous K-ras codon 11 $(\mathrm{GCT} \rightarrow \mathrm{CCT}$; Ala11Pro) and heterozygous codon 12 (GGT $\rightarrow \mathrm{GTT}$; Gly12Val) mutations. (E and F) Wild-type K-ras codon 11 and 12 sequences. (G) K-ras amplification products (157 bp) were digested with the restriction enzyme Bst $N \mathrm{I}$ and electrophoresed on 3\% agarose gel. L1, 50 bp ladder; lanes 1 and 3, wt samples; lane 2, heterozygous mut sample; lane 4, homozygous mut-positive control from the SW480 cell line; lane 5, undigested K-ras PCR product; L2, 100 bp ladder.

(x10), $2 \mu \mathrm{g}$ of total-RNA, $0.3 \mu \mathrm{g}$ of random primers, $25 \mathrm{mM}$ dNTPs and RNase-free water to a total volume of $19 \mu 1$ were heated at $65^{\circ} \mathrm{C}$ for $5 \mathrm{~min}$ in order to remove RNA secondary structures. Subsequently, each reaction was cooled at room temperature to allow the primers to anneal to the RNA, and $50 \mathrm{U}$ of StrataScript RT (an RNase H-deficient MMLV RT) along with $20 \mathrm{U}$ of RNase Block were added to each reaction. The final mix (volume $20 \mu \mathrm{l}$ ) was incubated for $10 \mathrm{~min}$ at $25^{\circ} \mathrm{C}$ for primer extension, and cDNA synthesis was conducted at $42^{\circ} \mathrm{C}$ for $60 \mathrm{~min}$. The reaction was terminated by heating at $72^{\circ} \mathrm{C}$ for $15 \mathrm{~min}$.

Real-time PCR. Differential mRNA expression levels of the three ras genes were measured using a real-time RT-PCR assay with SYBR-Green I. All primer pairs were designed to span at least one intron in order to avoid the amplification of contaminating genomic DNA along with the cDNA. Glyceraldehyde-3-phosphate dehydrogenase (GAPDH) was used as the internal control in order to normalise $\mathrm{K}-, \mathrm{H}-$ and $\mathrm{N}$-ras expression levels.

RNA primer sequences and the size of the ras and GAPDH PCR products were as follows: i) K-ras: sense primer, 5'GGGGAGGGCTTTCTTTGTGTA-3'; antisense primer, 5'-
GTCCTGAGCCTGTTTTGTGTC-3'; amplified sequence, 174 bp; ii) H-ras: sense primer, 5'-GGGGCAGTCGCGCCT GTGAA-3'; antisense primer, 5'-CCGGCGCCCACCACCA CCAG-3'; amplified sequence, 110 bp; iii) N-ras: sense primer, 5'-CTTCCTCTGTGTATTTGCCATCA-3'; antisense primer, 5'-GCACCATAGGTACATCATCCGA-3'; amplified sequence, 107 bp; iv) GAPDH: sense primer, 5'-GGAAGGT GAAGGTCGGAGTCA-3'; antisense primer, 5'-GTCATTG ATGGCAACAATATCCACT-3'; amplified sequence, 101 bp.

Amplification parameters for the real-time PCR were as follows: i) $\mathrm{K}$ - and N-ras amplification: denaturation at $95^{\circ} \mathrm{C}$ for $30 \mathrm{sec}$, annealing at $55^{\circ} \mathrm{C}$ for $30 \mathrm{sec}$ and extension at $72^{\circ} \mathrm{C}$ for $30 \mathrm{sec}$ for 40 cycles; ii) H-ras amplification: denaturation at $95^{\circ} \mathrm{C}$ for $30 \mathrm{sec}$, annealing at $65^{\circ} \mathrm{C}$ for $30 \mathrm{sec}$ and extension at $72^{\circ} \mathrm{C}$ for $30 \mathrm{sec}$ for 40 cycles; iii) GAPDH amplification: denaturation at $95^{\circ} \mathrm{C}$ for $30 \mathrm{sec}$, annealing at $60^{\circ} \mathrm{C}$ for $30 \mathrm{sec}$ and extension at $72^{\circ} \mathrm{C}$ for $30 \mathrm{sec}$ for 40 cycles.

Regarding the specifics of the real-time PCR procedure, $1 \mu 1$ cDNA from NP, AMT, AIT, CMT or CIT samples was amplified in a PCR reaction containing $2 \mathrm{X}$ Brilliant SYBRGreen I QPCR Master Mix, $300 \mathrm{nM}$ of each primer and $30 \mu \mathrm{M}$ ROX passive reference dye, for a final volume of $20 \mu \mathrm{l}$. The final extension step was followed by a melt curve analysis, in 
A.

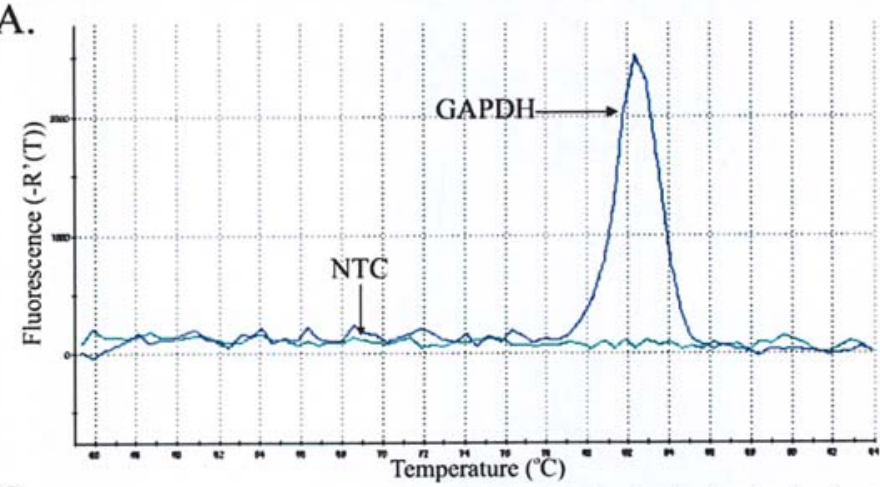

C.

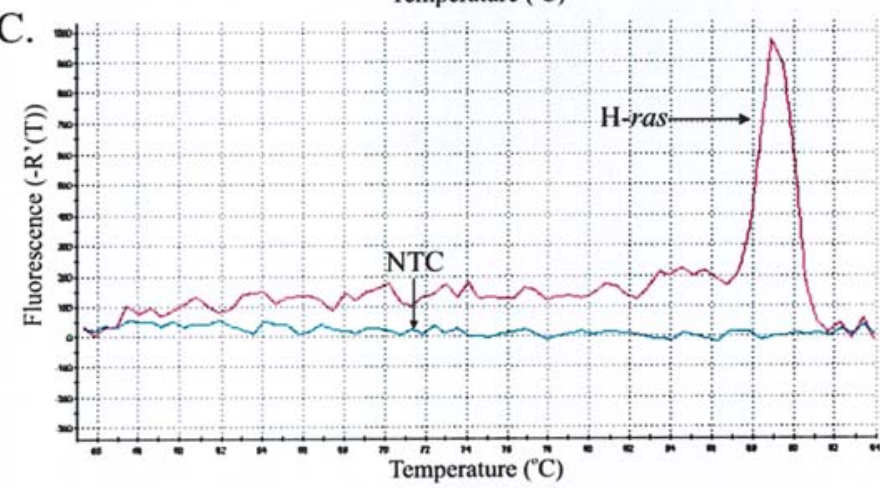

E.

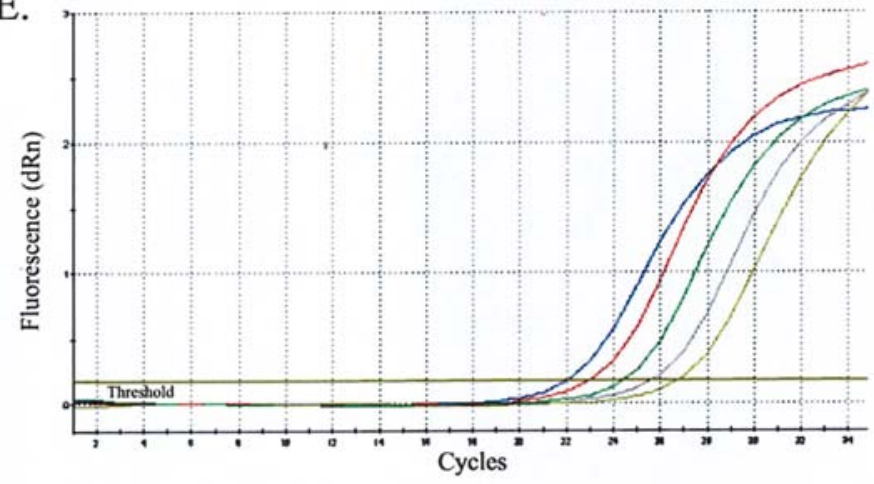

B.

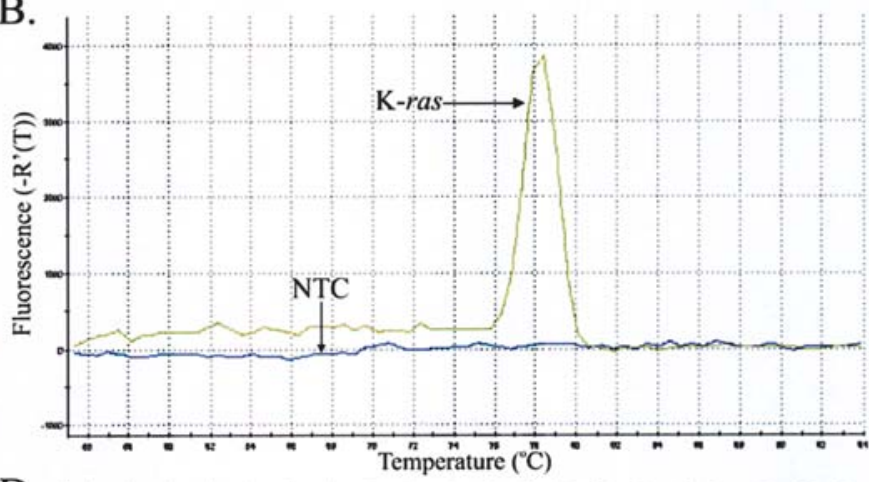

D.

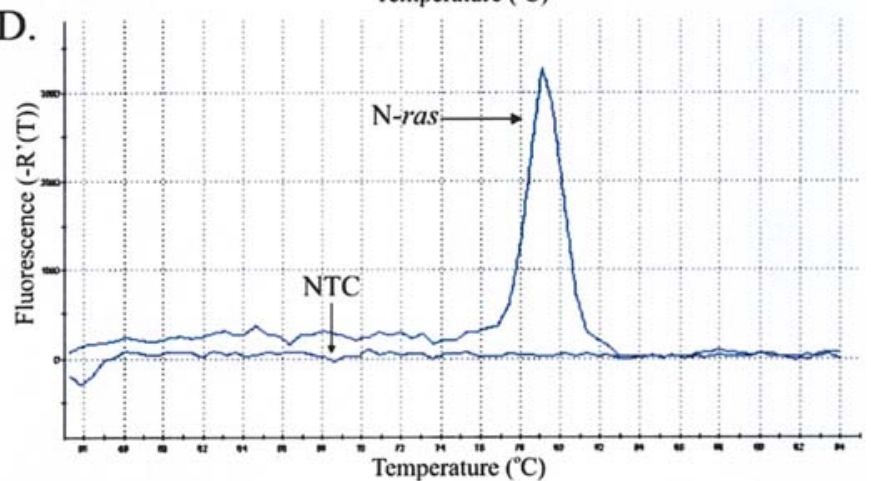

F.

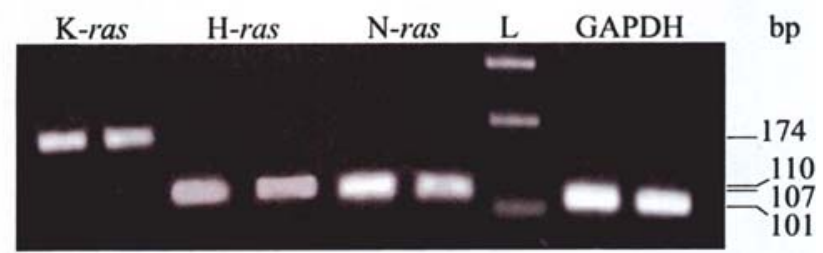

Figure 2. Indicative dissociation curves of (A) GAPDH, (B) K-ras, (C) H-ras and (D) N-ras. Single peaks for all genes and absence of peaks for the non-template controls demonstrates the exclusion of any genomic DNA contamination. (E) Amplification plot for the standard samples (2-fold dilutions of a cDNA pool), with which the standard curve was constructed. Standard curve reaction efficiency reached 100\%, slope -3.325 and Rsq $~ 1$. (F) Gel Analysis for the ras family genes, along with GAPDH (normaliser gene). L, DNA molecular ladder.

which the temperature was increased from 55 to $95^{\circ} \mathrm{C}$ at a linear rate of $0.2^{\circ} \mathrm{C} / \mathrm{sec}$ (Fig. 2). Data collection was performed during both annealing and extension with two measurements at each step, and at all times during the melt-curve analysis. All PCR experiments were conducted on an Mx3000P real-time PCR thermal cycler using software version 2.0 (Stratagene, La Jolla, CA). In order to verify the results of the melt-curve analysis, PCR products were analysed by electrophoresis in $2 \%$ agarose gel, stained with ethidium bromide and photographed on a UV light transilluminator. Two non-template controls were included in each PCR reaction. All reactions were run in triplicate, and ras transcript levels were calculated and normalised to each specimen's house-keeping gene mRNA (GAPDH) as well as to the appropriate calibrators. Relative quantification was analysed using the $\Delta \Delta \mathrm{Ct}$ method. Specifically, after amplification standard curves for both the ras genes and the internal control (GAPDH) were constructed from samples used in a series of consecutive dilutions. Ras and
GAPDH amplification efficiencies were the same, reaching $100 \%$. NP, adjacent and control turbinate data were first normalised against variation in sample quality and quantity. Normalised values to GAPDH, $\Delta \mathrm{Cts}$, were initially calculated using the following equation: $\Delta \mathrm{Ct}_{\text {sample }}=\mathrm{Ct}_{\mathrm{ras}}-\mathrm{Ct}_{\mathrm{GAPDH}} \cdot \Delta \Delta \mathrm{Ct}$ was then determined using the formula $\Delta \Delta \mathrm{Ct}=\Delta \mathrm{Ct}_{\mathrm{NP}^{\mathrm{P}}}-\Delta \mathrm{Ct}_{\text {turbinate }}$. Expression of the normalised (to GAPDH) ras genes in NPs, compared to the corresponding turbinate used as a calibrator, equalled 2- $\Delta \Delta \mathrm{ct}$. A 2 -fold increased value $(\geq 2)$ or decreased value $(\leq 0.5)$ was considered to be mRNA overexpression or down-regulation, respectively, in that NP sample.

Statistical analysis. mRNA levels were first evaluated by the one-sample Kolmogorov-Smirnov goodness of fit test in order to determine whether they followed a normal distribution pattern. According to the results, Pearson's correlation or the non-parametric Spearman rank correlation were used to examine their pair-wise relation and their association with 
A.

\begin{tabular}{|c|c|c|c|c|c|c|c|}
\hline \multirow{3}{*}{$\begin{array}{c}\text { patient } \\
\text { no }\end{array}$} & \multirow{3}{*}{\begin{tabular}{|c|}
$\begin{array}{c}\text { nasal polyp } \\
\text { stage }\end{array}$ \\
(grade) \\
\end{tabular}} & \multicolumn{6}{|c|}{ K-ras mutation analysis } \\
\hline & & \multirow{2}{*}{\multicolumn{3}{|c|}{ codon 11 (GCT-CCT) }} & \multicolumn{3}{|c|}{ codon $12(\mathrm{GGT}-\mathrm{GTT})$} \\
\hline & & & & AMT & $\mathrm{NP}$ & AIT & AMT \\
\hline & II & hom & hom & N/A & het & $w t$ & N/A \\
\hline 2 & II & hom & wt & N/A & het & wt & N/A \\
\hline 3 & II & wt & hom & N/A & hom & hom & N/A \\
\hline 4 & III & wt & $w t$ & N/A & hom & hom & N/A \\
\hline 5 & II & $w$ & hom & hom & het & hom & hom \\
\hline 6 & III & 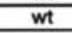 & $w t$ & $w t$ & $w t$ & wt & het \\
\hline 7 & $\frac{1}{1}$ & $w t$ & $w t$ & $m$ & $m$ & wt & wt \\
\hline 8 & II & wt & hom & wt & het & wt & $w t$ \\
\hline 9 & III & hom & wt & wt & wt & het & $w t$ \\
\hline 10 & III & wt & hom & hom & het & het & hom \\
\hline 11 & II & wt & $w_{t}$ & wt & wt & wt & het \\
\hline 12 & III & wt & $w t$ & wt & wt & wt & wt \\
\hline 13 & III & wt & $w t$ & wt & het & $w t$ & $w t$ \\
\hline 14 & II & hom & $w t$ & hom & $w t$ & wt & $w t$ \\
\hline 15 & IIII & wt & wt & wt & $w t$ & wt & wt \\
\hline 16 & III & wt & $w t$ & wt & wt & $w t$ & wt \\
\hline 17 & II & wt & wt & $w t$ & $w t$ & wt & wt \\
\hline 18 & III & $w_{t}$ & $w t$ & wt & $w t$ & $w t$ & $\mathrm{wt}$ \\
\hline 19 & $T$ & $\mathrm{wt}$ & $w t$ & $w t$ & $w t$ & $w t$ & $w t$ \\
\hline 20 & 1 & wt & $w t$ & $w t$ & wt & $w t$ & $w t$ \\
\hline 21 & III & $w t$ & $w t$ & $w t$ & $w t$ & $w t$ & het \\
\hline 22 & III & $w t$ & $w$ & $w t$ & $w t$ & $w t$ & $w t$ \\
\hline & & & & & & & \\
\hline
\end{tabular}

B.

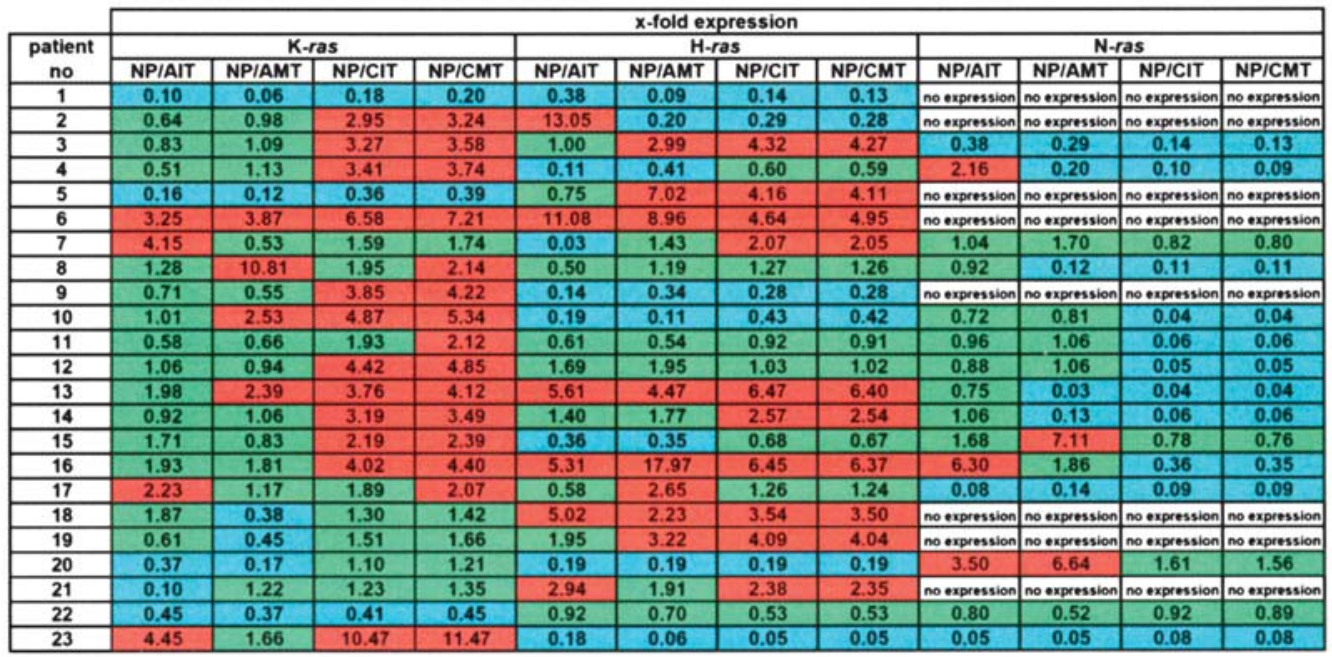

Figure 3. (A) Mutation analysis of K-ras in NPs, AITs and AMTs and (B) expression analysis of ras genes in NPs compared to the AIT, AMT, CIT and CMT regarding the stage of the polyp. A 2-fold increased $(>2)$ or decreased $(<0.5)$ value was considered mRNA overexpression or down-regulation, respectively, in that NP sample. Dark red denotes overexpression, green the same expression levels and light blue under-expression. Hom, homozygous mutation; Het, heterozygous mutation; wt, wild-type; N/A, not available.

continuous variables (age, stage of NP). The Mann-Whitney U and Kruskal-Wallis $\mathrm{H}$ test were used, when indicated by the analysis, to examine the correlation between ras expression status and various clinicopathological parameters following stratification. Differences in the incidence of ras mutations among tissues and polyp stage were calculated by the $\chi^{2}$ test. All statistical analyses were performed with SPSS 11.5 (SPSS, Chicago, IL). Statistical significance was set at the $95 \%$ level $(\mathrm{P}<0.05)$.

\section{Results}

This study was conducted in order to determine ras codon 12 point mutations as well as mRNA transcription levels of ras family genes in NPs. For the first part of our study, a sensitive PCR-RFLP assay was carried out along with sequencing of the PCR product. Regarding expression analysis, we initially calculated the normalised values of all target genes to GAPDH for all tissues (NPs, AITs, AMTs, CITs and CMTs) and compared the expression levels of the ras genes among NPs and the two types of calibrators: i) the corresponding AIT and AMT, and ii) the CITs and CMTs (Fig. 3).

Ras mutational analysis. Mutation analysis of the $\mathrm{K}-, \mathrm{H}-$ and $\mathrm{N}$-ras codon 12 was carried out in 23 patients. In addition to $\mathrm{GGT} \rightarrow \mathrm{GTT}$ mutations at codon 12 (Gly12Val) for K-ras, sequencing analysis also revealed $\mathrm{GCT} \rightarrow \mathrm{CCT}$ mutations at codon 11 (Ala11Pro). K-ras codon 11 mutations were found in 4/23 NPs (17\%), 5/23 AITs (22\%) and 3/19 AMTs (16\%), all of which were homozygous. K-ras codon 12 mutations were detected in $8 / 23$ polyps (35\%), 5/23 AITs $(22 \%)$ and 5/19 AMTs $(26 \%)$. No point mutation was detected in any of the control turbinates. In NPs, AITs and AMTs, respectively, 2/8 (25\%), 3/5 (60\%) and 2/5 (40\%) of the K-ras codon 12 mutations were homozygous, whereas 6/8 (75\%), 2/5 (40\%) and $3 / 5(60 \%)$ were heterozygous in the corresponding tissues. No K-ras codon 13 mutation was detected by direct sequencing in any of the tissues studied. K-ras codon 11 and 12 mutations were significantly more frequent in the more advanced stages (grades II and III) of the polyps in contrast to 
A.

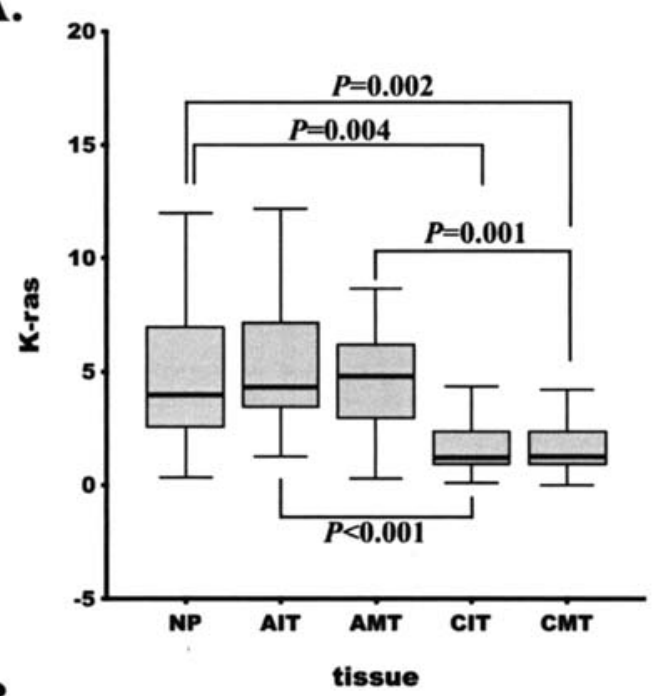

B.

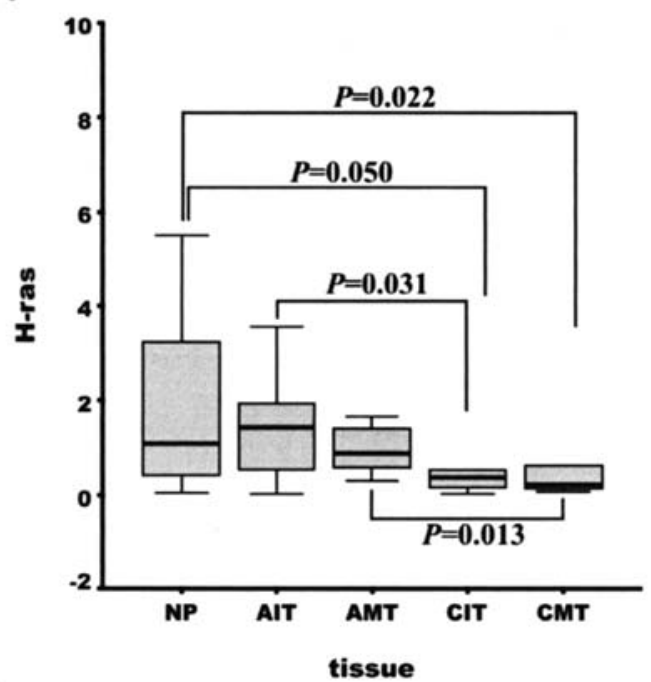

C.

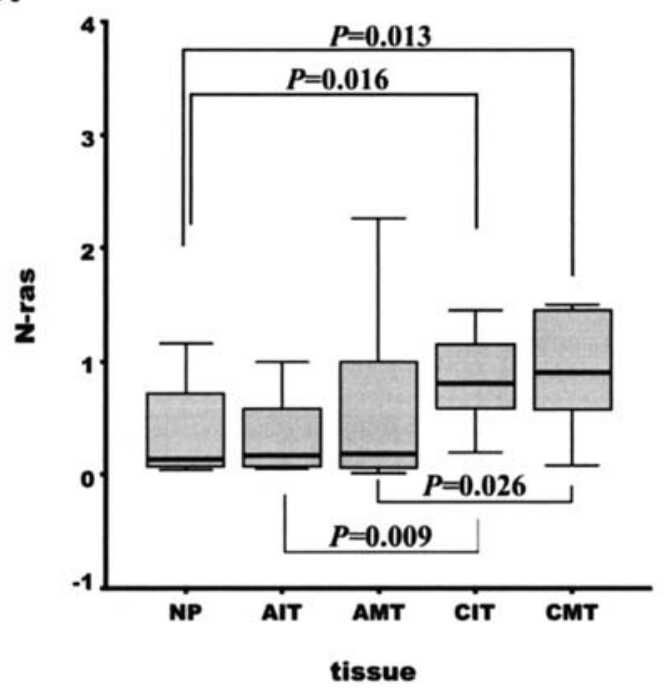

Figure 4. (A) K-ras, (B) H-ras and (C) N-ras expression levels in NPs, AITs, AMTs, CITs and CMTs. All ras normalised mRNA expression levels differed significantly among the tissues studied (K-ras, $\mathrm{P}<0.001$; H-ras, $\mathrm{P}=0.017$; N-ras, $\mathrm{P}=0.007$; Kruskal-Wallis test). $\mathrm{K}$ - and $\mathrm{H}$-ras transcription levels were significantly higher in NPs, AITs and AMTs as compared to CITs and CMTs, whereas N-ras presented exactly the opposite characteristics. Statistically significant differences in the expression levels of the ras genes between two different tissues are depicted (Mann-Whitney U test). Box-plots show the 25th, 50th (median), and 75th percentile values. Whiskers show the minimum and maximum values.

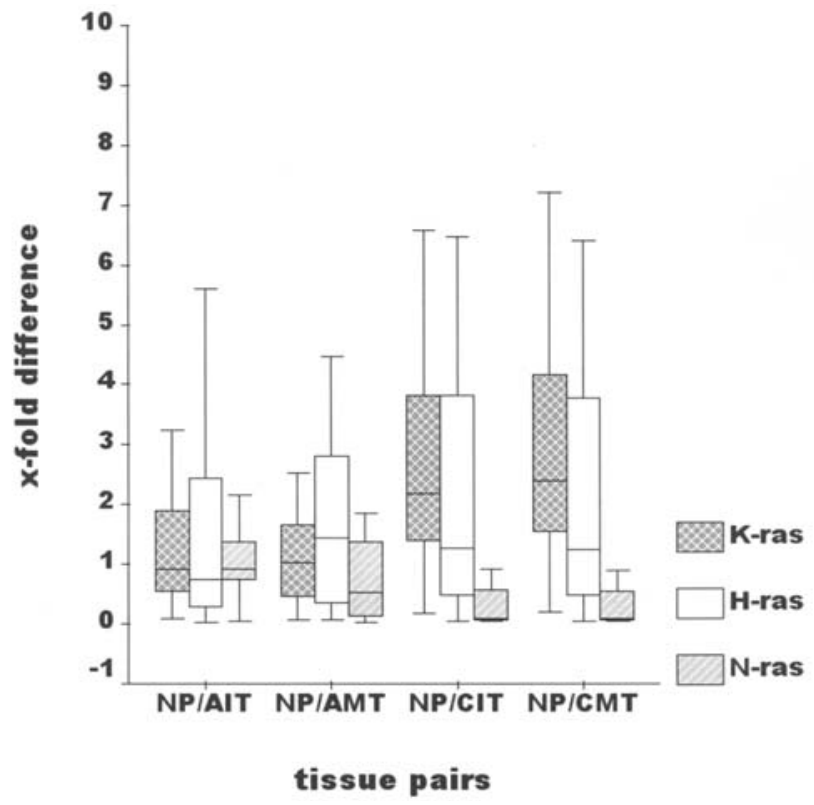

Figure 5. x-fold difference in expression levels between NPs and the two types of calibrators used (adjacent and control turbinates). K-ras was overexpressed in NPs as compared to CITs and CMTs and equally expressed in NPs and the AIT-AMTs. H-ras was stably overexpressed (mean 2.29-fold \pm 0.12 ) in NPs relative to all turbinates (adjacent and control), whereas N-ras was under-expressed in NPs relative to the control turbinates $(<0.5$-fold $)$ and stably expressed between NPs and adjacent turbinates. A 2-fold increased value $(\geq 2)$ or decreased value $(\leq 0.5)$ was considered mRNA overexpression or down-regulation, respectively, in NP versus the corresponding turbinate. Box-plots show the 25 th, 50th (median), and 75 th percentile values. Whiskers show the minimum and maximum values.

grade I polyps. Specifically, 3/4 K-ras codon 11 mutations $(75 \%)$ were detected in grade II polyps and $1 / 4$ in grade III polyps $(25 \%)$. K-ras codon 12 mutations were found in $5 / 8$ grade II polyps $(62.5 \%)$ and in $3 / 8$ grade III polyps $(37.5 \%)$. No grade I NP presented K-ras codon 11 or 12 mutations.

One H-ras codon 12 mutation, of grade III, was observed among the 23 polyps (4\%), while no H-ras codon 11 or 13 mutations were found in any of the other turbinates. Mutation analysis of codons 11, 12 and 13 of the N-ras gene was negative in all tissue samples tested.

Expression levels. In the expression levels of the ras family genes of the tissues studied, $\mathrm{K}$ - and $\mathrm{H}$-ras were expressed in all polyps and turbinates while N-ras was expressed in 15/23 NPs (65\%), 20/23 AITs (87\%), 17/18 AMTs (94\%), 11/13 CITs (85\%) and 12/13 CMTs (92\%).

The ras normalised mRNA expression levels differed significantly among the tissues studied (NPs, AITs, AMTs, CITs and CMTs) (K-ras, $\mathrm{P}<0.001$; H-ras, $\mathrm{P}=0.017$; N-ras, $\mathrm{P}=0.007$; Kruskal-Wallis test) (Fig. 4). Specifically, K-ras transcript levels were higher in NPs compared to CITs and CMTs ( $\mathrm{P}=0.004$ and 0.002, respectively). Moreover, K-ras expression levels were elevated in the AITs and AMTs in comparison to the corresponding control turbinates (AIT-CIT, $\mathrm{P}<0.001$ and AMT-CMT, $\mathrm{P}=0.001)$. Similarly, H-ras mRNA levels were up-regulated in NPs compared to the control turbinates (NP-CIT, $\mathrm{P}=0.05$; NP-CMT, $\mathrm{P}=0.022$ ). Likewise, $\mathrm{H}-$ ras was expressed at higher levels in the adjacent turbinates as compared to the corresponding control turbinates (AIT-CIT, $\mathrm{P}=0.031$; AMT-CMT, $\mathrm{P}=0.013$ ). In contrast to $\mathrm{K}$ - and $\mathrm{H}-$ ras, 

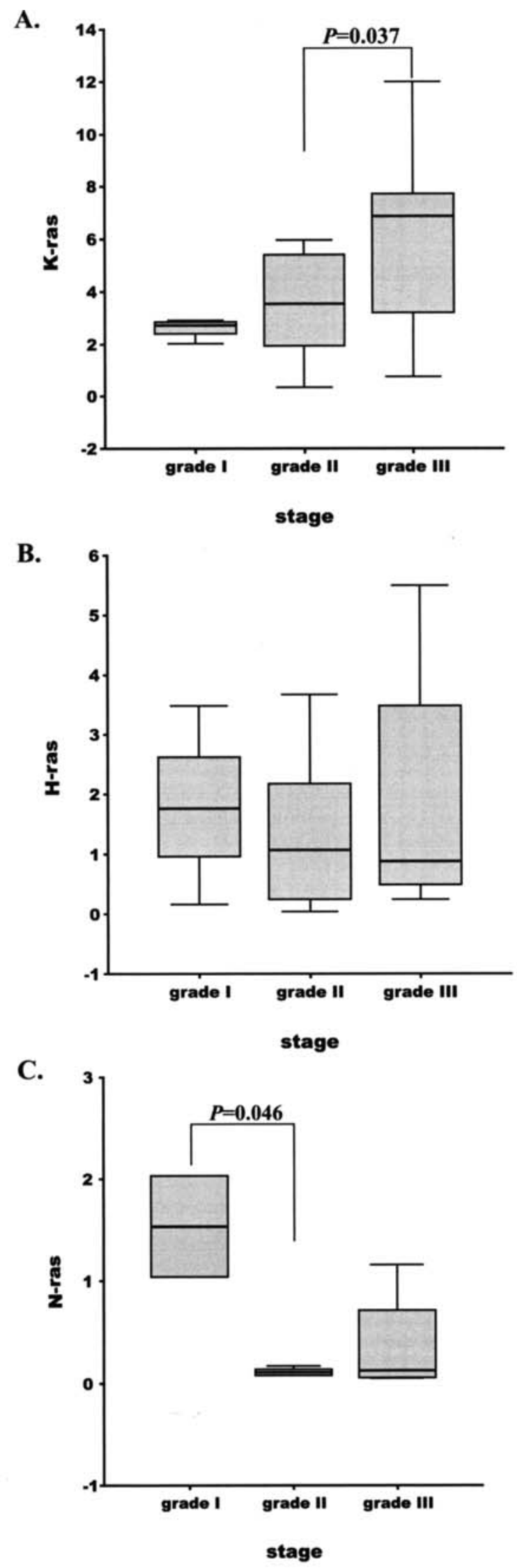

Figure 6. K-ras mRNA levels differed based on the stage of the NP (marginal $\mathrm{P}=0.067$; Kruskal-Wallis). (A) K-ras transcript levels were higher in grade III compared to grade II ( $\mathrm{P}=0.037$, Mann-Whitney) and I NPs. (B) H-ras mRNA were similar in all stages of NPs. (C) N-ras expression levels were higher in grade I compared to grade II ( $\mathrm{P}=0.046$, Mann-Whitney) and III NPs. Results are expressed as median and 25th-75th percentile. Whiskers show the minimum and maximum values.
$\mathrm{N}$-ras expression levels were lower in the NPs and adjacent turbinates than in the control turbinates (NP-CIT, $\mathrm{P}=0.016$; NP-CMT, $\mathrm{P}=0.013$; AIT-CIT, $\mathrm{P}=0.009$; AMT-CMT, $\mathrm{P}=0.026)$.

Fold-difference in expression levels between NPs and the adjacent and control calibrators (inferior and middle turbinates) is depicted in Fig. 5. K-ras presented stable expression levels between NPs and their adjacent turbinates (mean fold-change between the tissue pairs NP-AIT and NPAMT was 1.34 and 1.76, respectively). Interestingly, K-ras mean fold-change between NPs, CITs and CMTs was 2.89 and 3.17 , respectively. H-ras was stably overexpressed (mean, 2.29-fold \pm 0.12 ) in NPs relative to all the turbinates (adjacent and controls), whereas N-ras was underexpressed in NPs relative to the control turbinates $(<0.5$-fold) and stably expressed between NPs and adjacent turbinates (mean foldchange, 1.42 and 1.45 , respectively).

Ras expression levels compared to clinicopathological characteristics. K-ras mRNA levels differed according to the stage of the NP (marginal P=0.067; Kruskal-Wallis) (Fig. 6). $\mathrm{K}$-ras transcript levels were higher in grade III compared to grade II ( $\mathrm{P}=0.037$; Mann-Whitney $\mathrm{U}$ ) and I NPs. In contrast, $\mathrm{N}$-ras expression levels were higher in grade I than in grade II ( $\mathrm{P}=0.046$; Mann-Whitney U) and III NPs. H-ras transcript levels did not present statistically significant differences in terms of the staging of the NPs. All ras expression levels were higher in aspirin intolerant versus tolerant patients $(\mathrm{P}=0.016$; $\left.\chi^{2}\right)$. Moreover, ras transcription levels did not present any significant correlation with the presence of a point mutation in the specific tissue. NP occurrence was more frequent in men than in women $\left(\mathrm{P}=0.003 ; \chi^{2}\right)$ and patients over the age of 40 years were more prone to the disease $\left(\mathrm{P}=0.022 ; \chi^{2}\right)$. No other statistically significant correlation was established between ras mRNA levels and sex, age, smoking or drinking habits.

$m R N A$ pair-wise expression analysis. The Spearman test was run in order to detect possible correlations for the evaluation of ras co-expression patterns in the groups of NP, AIT, AMT, CIT and CMT. Significant negative correlations arose between K-ras and N-ras in the NPs and AITs ( $\mathrm{P}=0.009$ and 0.003 , respectively), whereas no correlation was present between the AMTs and control turbinates.

\section{Discussion}

$\mathrm{K}$-ras is frequently mutated in codon 12 , altering the GTPbinding activity of the protein and rendering it a powerful transforming oncogene (21). Mutations of K-ras have been detected in more than $80 \%$ of human pancreatic tumours (22), in $38 \%$ of colon cancer specimens (23), in $31 \%$ of small intestine cancers (24), in $26 \%$ of primary hepatic malignant tumours $(25)$, in $10-40 \%$ of endometrial carcinomas $(26,27)$ and in $6.5-12 \%$ of breast tumours $(19,28)$. Mutations of K-ras are also common in lung cancer, where $30 \%$ of adenocarcinomas (29) and $21 \%$ of squamous-cell carcinomas (30) harbour K-ras mutations in codon 12 .

In the present study, we evaluated the incidence of K-ras codon 11 and 12 mutations in NPs for the first time. Our results demonstrate that a significant proportion of polyps 
harbour K-ras codon 11 and 12 mutations (17 and 35\%, respectively). Our finding, that the adjacent turbinates also harbour a similar percentage of K-ras mutations (codon 11: AIT, 22\%; AMT, 16\%; codon 12: AIT, 22\%; AMT, 26\%) as opposed to the control turbinates where K-ras mutations were totally absent, suggests that the mutational activation of the K-ras gene comprises a common feature of the NP formation procedure. Considering that NPs usually originate in the middle meatus, we hypothesise that $\mathrm{K}$-ras mutations might be an early event in the formation of this benign tumour. Our discovery of K-ras mutations in NPs is in agreement with the concept that K-ras-dependent tumour development results in the formation of less aggressive neoplasms (28). Reinforcing the latter, K-ras mutations have also been found in hyperplastic polyps of the colon, which are not considered precancerous lesions, at a high frequency (47\%) $(23,31)$. H-ras mutations were found in only $4 \%$ of the NPs (1/23) and no N-ras mutation was detected.

In another adenomatous type disease, familial adenomatous polyposis (FAP), patients typically develop hundreds to thousands of colorectal tumours (adenomas or adenomatous polyps) due to a single gene, $A P C$, which has been characterised as the disease initiator. It is believed that $A P C$ acts as a 'gatekeeper' against colonic epithelial cell proliferation. Consequently, mutations in this gatekeeper initiate the neoplastic process, while tumour progression results from mutations in other genes such as K-ras and p53 (32). In our study, K-ras codon 11 and 12 mutations were more frequent in grade II and III than in grade I NPs. This observation could lead to the assumption that ras mutations occur as the polyps increase in size. However, the small number of grade I NPs $(n=3)$ does not strongly support this concept. On the contrary, our discovery of ras mutations in the adjacent turbinates and not in the controls suggests that K-ras mutations comprise a rather early event in the formation of this benign tumour. We could therefore suggest a possible model where K-ras by itself (resembling the function of $A P C$ in FAP) or in combination with other genetic changes (e.g. tumour suppressor p53 or p16 inactivation) could act as a similar gatekeeper, leading to benign tumours of the adenoma type, such as nasal and colorectal polyps. In the present study, support is provided by the observation that K-ras mutations were present both in the NPs and in the adjacent turbinates, the majority of which were characterised by a considerable level of hyperplasia. These hyperplastic cells, containing the mutant K-ras gene, have possibly little or no potential to form clinically malignant tumours instead of NPs.

Expression levels. Eleven polyps (48\%) exhibited elevated expression of at least one of the ras family genes compared to the AITs and AMTs, whereas 17 (74\%) and $20(87 \%)$ patients displayed elevated expression of at least one of the ras family genes compared to the CITs and CMTs, respectively. This suggests that overexpression is also an important mechanism of ras gene activation in nasal polyposis.

K-ras presented higher expression levels in the NPs than in the control turbinates, H-ras was stably overexpressed in the NPs compared to all adjacent and control turbinates and $\mathrm{N}$-ras presented lower transcription levels in the NPs than in the control turbinates. These findings suggest that the over- production of $\mathrm{p} 21^{\text {ras }}$ is due not to the activation of only one member of the ras family, but to both the $\mathrm{K}$ - and $\mathrm{H}$-ras genes activation in nasal polyposis. The above observation indicates that the overproduction of $\mathrm{p} 21^{\text {ras }}$ in NPs, regardless of which gene is responsible for the overexpression, is probably required for the development of tumourigenic potential in nasal mucosa. On the other hand, it is worth underlining the fact that the adjacent turbinates also exhibit higher levels of $\mathrm{K}$ - and $\mathrm{H}-\mathrm{ras}$ mRNA compared to the control turbinates, which suggests that p $21^{\text {ras }}$ overproduction could also be critical to the hypertrophy that distinguishes most of the adjacent turbinates. Our finding, that N-ras presents lower transcription levels in NPs as compared to both the adjacent and control turbinates, leads us to the hypothesis that either N-ras possesses a weaker tumourigenic potential as compared to $\mathrm{K}$ - and $\mathrm{H}-$ ras, or that the down-regulation of $\mathrm{N}$-ras is an alternative important feature in NP formation, working in an as yet unknown way. In any case, ras genes have been shown to possess the dual role of oncogene or onco-suppressor depending on the disease context (18). Based on our results, we hypothesise that wild-type Nras works as a tumour-suppressor gene, antagonising the oncogenic properties of $\mathrm{K}$ - and $\mathrm{H}$-ras in the formation of NPs. According to our findings N-ras is negatively correlated with K-ras transcript levels in the NPs and the AITs, but not in the control mucosa. More studies are needed, however, to reveal the intrinsic role of the ras family genes in NP formation.

NPs that presented K- and H-ras overexpression compared to the control turbinates (either inferior and/or middle) were of advanced stage. In the case of K-ras, $7 / 15$ polyps (46.6\%) that presented overexpression compared to the CIT and/or CMT were of grade II and 8/15 $(53.3 \%)$ of grade III. For $\mathrm{H}-$ ras, $3 / 10(30 \%)$ were of grade II and 5/10 (50\%) of grade III, respectively. Likewise, in lung, stomach, endometrial and ovarian lesions, ras overexpression appeared at a later stage of tumourigenesis (33). We can only speculate that ras genes activation in nasal polyposis is initially based on activating mutations that occur rather early in the process, and that this activation is reinforced and augmented by ras overexpression, a feature of advanced stage NPs.

To our knowledge, this is the first study to report on the incidence of mutations as well as on mRNA expression levels of the ras family genes in human NPs. In summary, our findings indicate that $\mathrm{K}$ - and $\mathrm{H}$-ras mutations are present in NPs and their adjacent turbinates, in contrast to healthy control mucosa. We could therefore suggest a role for K-ras in the development in nasal polyps. Furthermore, we provide evidence that $\mathrm{K}$ - and $\mathrm{H}$-ras are transcriptionally activated in NPs and their adjacent turbinates, indicating that the overproduction of $\mathrm{p} 21^{\text {ras }}$ is probably required in the multistage process of the disease, and corroborating that the origin of NPs is in the middle turbinate and middle meatus. The expression levels of ras family genes did not correlate to the occurrence of point mutations, indicating that the different genetic alterations are not mutually dependent. Probably, the occurrence of both ras overexpression and point mutations in codons 11 and/or 12 provide the necessary genetic changes for NP formation. Moreover, mutations within the promoters of the ras family genes, in combination with mRNA overexpression, could possibly explain the activation of ras 
family genes in nasal polyposis without excluding other possible mechanisms, such as the imbalance of chromosomes (resulting in gene amplification), that could act synergistically.

More in-depth studies, utilising large numbers of samples, are required in order to clarify the precise role of the mutational and expressional aberrations of ras genes in nasal polyposis.

\section{References}

1. Lund VJ: Diagnosis and treatment of nasal polyps. BMJ 311: 1411-1414, 1995.

2. Connell JT: Nasal hypersensitivity. In: Comprehensive Immunology. Gupta S and Good RA (eds.) Plenum Publ. Corp., New York, pp6, 1979.

3. Cauna N, Manzetti GW, Hinderer KH and Swanson EW: Fine structure of nasal polyps. Ann Otol Rhinol Laryngol 81: 41-58, 1972 .

4. Kakoi $\mathrm{H}$ and Hiraide F: A histological study of formation and growth of nasal polyps. Acta Otolaryngol 103: 137-144, 1987.

5. Roche WR, Williams JH, Beasley R and Holgate ST: Subepithelial fibrosis in the bronchi of asthmatics. Lancet 1: 520-524, 1989.

6. Pronk GJ and Bos JL: The role of p21 ras in receptor tyrosine kinase signalling. Biochem Biophys Acta 1198: 131-147, 1994.

7. Dokianakis DN, Sourvinos G, Sakkas S, et al: Detection of HPV and ras gene mutations in cervical smears from female genital lesions. Oncol Rep 5: 1195-1198, 1998.

8. Koffa M, Malamou-Mitsi V, Agnantis NJ and Spandidos DA Mutational activation of K-ras oncogene in human breast tumours. Int J Oncol 4: 573-576, 1994.

9. Roth S, Partanen T, Suitiala T, Anttila S, Ojajärvi A, Hemminki K, Vainio $\mathrm{H}$ and Husgafvel-Pursiainen K: Molecular analysis of occupational cancer: infrequent $\mathrm{p} 53$ and ras mutations in renalcell cancer in workers exposed to gasoline. Int J Cancer 14: 492-496, 1997.

10. Kim TY, Bang YJ, Kim WS, et al: Mutation of ras oncogene in gastric adenocarcinoma: association with histological phenotype. Anticancer Res 17: 1335-1340, 1997.

11. Mulder MP, Keijzer W, Boot AJM, et al: Activated ras genes in human seminomas: evidence for tumour heterogeneity. Oncogene 4: 1345-1351, 1989.

12. Hongyo T, Buzard GS, Palli D, et al: Mutations of the K-ras and p53 genes in gastric adenocarcinomas from a high-incidence region around Florence, Italy. Cancer Res 55: 2665-2672, 1995.

13. Suzuki Y, Orita M, Shiraishi M, Hayashi K and Sekiya T: Detection of ras gene mutations in human lung cancers by singlestrand conformation polymorphism analysis of polymerase chain reaction products. Oncogene 5: 1037-1043, 1990.

14. Grimmond SM, Raghavan D and Russell PJ: Detection of rare point mutation in Ki-ras of a human bladder cancer xenograft by polymerase chain reaction and direct sequencing. Urol Res 20: 121-126, 1992.
15. Spandidos DA and Wilkie NM: Malignant transformation of early passage rodent cells by a single mutated human oncogene. Nature 310: 469-475, 1984

16. Field JK and Spandidos DA: The role of ras and myc oncogenes in human solid tumors and their relevance in diagnosis and prognosis. Anticancer Res 10: 1-22, 1990.

17. Kiaris H, Spandidos DA, Jones AS, et al: Mutations, expression and genomic instability of the H-ras proto-oncogene in squamous cell carcinomas of the head and neck. Br J Cancer 72: 123-129, 1995.

18. Spandidos DA, Sourvinos G, Tsatsanis C and Zafiropoulos A Normal ras genes: Their onco-suppressor and pro-apoptotic functions (Review). Int J Oncol 21: 237-241, 2002.

19. Miyakis S, Sourvinos G and Spandidos DA: Differential expression and mutation of the ras family genes in human breast cancer. Biochem Biophys Res Commun 251: 609-612, 1998.

20. Malm L: Assessment and staging of nasal polyposis. Acta Otolaryngol 117: 465-467, 1997.

21. Kiaris H and Spandidos DA: Mutations of ras genes in human tumors. Int J Oncol 7: 413-421, 1995.

22. Tada M, Omata M, Kawai S, et al: Detection of ras gene mutations in pancreatic juice and peripheral blood of patients with pancreatic adenocarcinoma. Cancer Res 53: 2472-2474, 1993.

23. Spandidos DA, Glarakis IS, Kotsinas A, Ergazaki M and Kiaris H Ras oncogene activation in benign and malignant colorectal tumours. Tumori 81: 7-11, 1995.

24. Spandidos DA, Liloglou T, Arvanitis D and Gourtsoyiannis NC: Ras gene activation in human small intestinal tumors. Int $\mathrm{J}$ Oncol 2: $513-518,1993$

25. Tada M, Omata M and Ohto M: Analysis of ras gene mutations in human hepatic malignant tumors by polymerase chain reaction and direct sequencing. Cancer Res 50: 1121-1124, 1990.

26. Ignar-Trowbridge D, Risinger JI, Dent GA, et al: Mutations of the Ki-ras oncogene in endometrial carcinoma. Am J Obstet Gynecol 167: 227-232, 1992.

27. Enomoto T, Inoue M, Perantoni AO, et al: K-ras activation in premalignant and malignant epithelial lesions of the human uterus. Cancer Res 51: 5308-5314, 1991

28. Koffa M, Malamou-Mitsi V, Agnantis NJ and Spandidos DA: Mutational activation of the K-ras oncogene in human breast tumors. Int J Oncol 4: 573-576, 1994.

29. Rodenhuis S and Slebos RJ: Clinical significance of ras oncogene activation in human lung cancer. Cancer Res 52: S2665-S2669, 1992.

30. Rosell R, Li S, Skacel Z, et al: Prognostic impact of mutated K-ras gene in surgically resected non-small cell lung cancer patients. Oncogene 8: 2407-2412, 1993

31. Glarakis IS, Savva S and Spandidos DA: Activation of the ras genes in malignant and premalignant colorectal tumors. Oncol Rep 5: 1451-1454, 1998.

32. Kinzel KW and Vogelstein B: Lessons from hereditary colorectal cancer. Cell 87: 159-170, 1996

33. Zachos G and Spandidos DA: Transcriptional regulation of the H-ras 1 proto-oncogene. Gene Ther Mol Biol 1: 629-639, 1998. 